\begin{tabular}{|c|c|c|}
\hline $\bar{z}$ & $\begin{array}{l}\text { International Journal of Current Research in } \\
\text { Biosciences and Plant Biology }\end{array}$ & $y=$ \\
\hline & Volume 7 •Number 6 (June-2020) • ISSN: 2349-8080 (Online) & 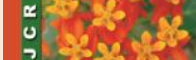 \\
\hline $\begin{array}{l}\text { EXCELLENT } \\
\text { PUBLISHERS }\end{array}$ & 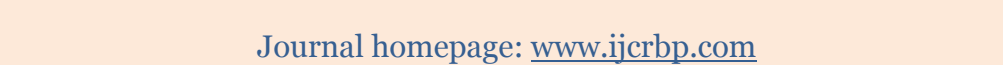 & \\
\hline
\end{tabular}

\title{
Regulation of induction of phenylalanine ammonia lyase and its role in production of phenolic compounds in plants
}

\author{
Pratik Talukder* \\ Department of Biotechnology, University of Engineering and Management, Kolkata, India \\ University Area, Plot, Street Number 03, Action Area III, B/5, Newtown, Kolkata, West Bengal - 700 156, India \\ *Corresponding author; e-mail: pratik.talukder@uem.edu.in; Phone: (+91) 94333-77397
}

\section{Article Info}

Date of Acceptance:

21 May 2020

Date of Publication: o6 June 2020

Keywords

Enzyme induction

Phenylalanine ammonia lyase

(PAL)

Phenylpropanoid

Plant growth regulators

Polyphenol

\section{Introduction}

Phenolic compounds are ubiquitous in plants which collectively synthesize several thousand different chemicals. These compounds are characterized by hydroxylated aromatic ring. Among different phytochemicals phenolic compounds are extensively studied and have been exploited in different areas of plant research. A broad spectrum of polyphenolic compound includes simple molecules like phenolic acids to large polymers like tannins. Analytical characterization of a wide range of enzymes participating in the biosynthetic pathway of polyphenol production revealed that PAL is the

principal enzyme of this pathway in plants. Phenylalanine ammonia lyase (PAL) (E.C. 4.1 .1.5) is currently known to be the most studied enzyme involved in the secondary metabolism of plants. The enzyme was discovered in barley seedlings by Koukol and Conn in 1961. PAL catalyzes the first committed step in the biosynthesis of a diverse range of phenylpropanoid-derived secondary products such as flavonoids and isoflavonoids, coumarins, and lignins (Hanson and Havir, 1970; Shine et al., 2016). The reaction catalyzed by PAL is a spontaneous non oxidative deamination of Lphenylalanine which yields trans-cinnamic acid and ammonia (Hanson and Havir, 1968; Jun et al., 2018).
\end{abstract}


PAL is the first and committed enzyme of the phenyl propanoid pathway that channels L-Phenylalanine from the general metabolic pool to the synthesis of trans-cinnamic acid which is further transformed into several polyphenolic compounds. Apart from this, PAL plays important role in the production of anthocyanin and other pigments (Holton and Cornish, 1995; de Sousa et al., 2020) and synthesis of flavonoid modulation factor (Wiesshaar and Jenkins, 1998). It has been well documented that several physical, chemical and biological factors play a major role in the induction of PAL at genetic level. Different types of stimuli such as light, tissue wounding, pathogenic attack, temperature, different concentration of plant growth regulators, metals, gamma and UV irradiation affects the de novo synthesis of the enzyme. Being a highly inducible enzyme PAL can be induced easily by different such stimuli.

Therefore, we have attempted to discuss some facts related to the enzymology of PAL and more emphasis is given on the biological aspects of regulation of the induction of PAL by various stimuli and its role in producing polyphenolic compounds in plants.

\section{Distribution of PAL in other genera}

Other than plants, PAL is reported to be present in other organisms too. Among microorganisms, it is present abundantly in yeast, mainly in Red yeast family Rhodotorula, and also in Sporobolo mycesroseus and Sporidiobolous pararoseus (Fritz et al., 1976). PAL helps to use Lphenylalanine as a source of nitrogen and carbon in microorganisms (Fritz et al., 1976). This enzyme is widely distributed in higher plants (Koukal and Conn, 1961), some fungi (Sikore and Marzluff, 1982), cyanobacteria (Albert et al., 1977) and Streptomyces (Bezanson et al., 1970). However, it is absent in true bacteria and animal tissues.

\section{Enzymatic activity of PAL}

PAL catalyses the elimination of ammonia and the pro-3s hydrogen from L-phenylalanine to form trans-cinnamate, the first committed step for biosynthesis of phenylpropanoid skeleton in higher plants (Hanson and Havir, 1981). PAL doesn't require the involvement of any cofactors for its activity. Purified PAL from different plant sources has a molecular mass in the range of $270-330 \mathrm{kDa}$ (Camm and Towers, 1973; Watanbe et al., 1992). PAL is a tetramer with identical subunits. Pairs of monomers form a protomer and it has a single active sight (Camm and Towers, 1973). Studies revealed the $\mathrm{Km}$ of the enzyme is in the range of $0.3 \times \mathrm{lo}^{-4}$ to $1.5 \times 10^{-2} \mathrm{M}$. Studies on substrate specificity of PAL revealed that it is highly specific for L-Phe and to a lesser extent to L-Tyr. D-Phe and D-Tyr do not serve as substrates of PAL; rather they act as competitive inhibitors of PAL (Ogata et al., 1967; Hodgins, 1971). According to Kyndt et al., 2002; substrate specificity of PAL varies greatly from species to species. PAL from dicotyledonous plants, is highly specific to L-Phe. On the other hand, in some photosynthetic bacteria, it shows higher specificity for L-Tyr. Three dimentional structure of PAL has been recently discovered by Calabrase et al. (2004) using X-ray crystallography.

\section{Factors influencing the induction of PAL}

An increased level of PAL activity is often referred to in the literature as an induction of the enzyme although it is generally understood that an inducible enzyme is one which is synthesized de novo in response to an external stimulus.

\section{Effect of light}

Among the stimuli examined, greatest effort has been made on the mechanism by which different qualities of light (white, red/far red, blue, UV) influences the level of PAL (Camm and Towers, 1977). The effect of light on levels of PAL has received a great deal of attention as a result of Zucker's discovery of the increased activity of PAL in potato slices incubated under white light. White light is first shown to induce PAL in potato tuber slices by Zucker (Zucker, 1965; Zucker, 1972).Induction of PAL causes an increase in the content of polyphenols especially chlorogenic acid (Zucker, 1965; Lamb and Rubery, 1976). Parsley cell suspension culture shows an UV-dependent PAL response resulting in flavonol formation (Hahlbrock et al., 1976). Involvement of phytochrome was demonstrated in etiolated pea (Lamb, 1979), mustard (Shields et al., 1982) and radish seedlings (Amrhein and Gerhardt, 1979), and Helianthus tuberosus tubers (Lamb, 1982). Several studies have shown that a short period of 
illumination with red light(R) followed by dark incubation causes an increase in PAL activity. In recent studies, some groups have shown that a brief illumination with far-red (FR) suppresses the response of PAL to $\mathrm{R}$. However, it has been recently reported that FR illumination increases PAL levels in etiolated tissue (Dixon and Fuller, 1976; Lamb, 1979; Noe and Seitz, 1982; Havir, 1981)). The increased level of PAL in etiolated radish seedlings has been correlated with the change of the amount of phytochrome (Duchesne et al., 1977; Amrhein and Gerhardt, 1979; Fosket, 1979; Trewavas, 1979) by a group of researchers.

Apart from exhibiting R-FR sensitivity, many of the systems also show sensitivity to blue light. In a study on Heliunthus tuberosus, incubation under white, red (660-680 $\mathrm{nm}$ ), and blue light (427 nm) has shown an increase in PAL induction (Nitsch and Nitsch, 1966). Long term irradiation with blue light in gherkin seedlings has shown a greater induction and accumulation of PAL (Schopfer and Mohr, 1972).

The problem of phytochrome involvement in PAL synthesis has not yet resolved. There is substantial evidence, for phytochrome mediated stimulation in pea, buckwheat, mustard and radish tissue; however, in other plants it is obscure and response to blue light may involve a different pigment.

\section{Effect of wounding, infection and ethylene}

Excision and wounding are also known to increase PAL levels in many plants (Camm and Towers, 1977). Some groups have shown that there is an increase in the induction of PAL upon wounding in pea seedlings (Hyodo and Yang, 1971), citrus fruit peel (Riov et al., 1969), excised bean axes (Sondheimer et al., 1968), buckwheat (Amrhein and Zenk, 1971) and gherkin (Engelsma, 1968). This effect may be ascribed to the production of ethylene, because wounding of a tissue stimulates the endogenous production of ethylene and the effect of added ethylene on most tissues is to give rise to an increased production of PAL. In some other studies they have shown there is an increase in PAL induction in citrus peel and pea seedlings when treated with gamma (Riov et al., 1968) and UV rays (Hadwiger and Schwochau, 1971) respectively. These effects could be a response due to the production of ethylene as a result of tissue injury. In a recent study on rosemary (Rosmarinus officinalis L.) showed that low doses of gamma treatment during callus culture causes minor tissue damage and hence production of ethylene which causes enhanced induction of PAL and subsequent increase in polyphenol production (Hossam et al., 2011).

PAL is also induced in response to infection by plant pathogens. Ethylene is also produced by plants following infection by a pathogenic organism. This may be responsible for triggering PAL production in plants and callus cultures infected with different pathogens. Studies in bean leaves following infection in tobacco infected with tobacco mosaic virus (Paynot et al., 1971) or Pseudomonas solanacearum (Pegg and Sequeria, 1968), in sweet potato infected with Ceratocystis fimbriata (Minamikawa and Uritani, 1965) and in soybean infected with Helminthosporium carbonum (Biehn et al., 1968) have shown an increase in PAL induction compared to that of untreated sample.

\section{Effect of plant growth regulators}

Little is known about the mechanism by which plant growth regulators influence induction of PAL in plants. Although several groups had worked on the effect of exogenous addition of plant growth regulators on PAL induction; however, the actual mechanism is yet to be solved. In a study with dark-grown bean (Phaseolus vulgaris) callus PAL activity increased within few days of callus culture when treated with lesser amount of exogenous auxin and higher amount of exogenous cytokinin (Jones and Northcte, 1981)). Dixon and Fuller (Dixon and Fuller, 1976) have also observed an increase in specific activity of PAL on lowering the auxin concentration. According to a recent study, gibberellin treatment increased PAL production and lignification in dwarf pea plants, but only when the plants are held in light (Cheng and Marsh, 1968). In pea and other plants gibberellic acid has been reported to promote PAL activity and lignifications (Riov et al., 1969). However, according to Fry et al. (1979), gibberelic acid repressed PAL activity in spinacia suspension cultures. Hemzmann and Seltz (1977) reported that gibberellic acid repressed anthocyanin synthesis and de novo synthesis of PAL in Daucus suspension cultures. As different plant growth 
regulator regulates PAL induction in different ways in plants and even during different developmental phases; so, it is very difficult to deduce any particular pattern of PAL induction by a specific plant growth regulator.

\section{Effect of metals on PAL activity}

Presence of heavy metals in the environment affects plant metabolism and induces different mechanisms, which enable them to counteract with the direct and indirect negative influences caused by uptake and translocation of these heavy metals within tissues. Cadmium (Cd) has no known physiological function in plants, while copper $(\mathrm{Cu})$ is an essential plant micronutrient (Owen, 1982).Notwithstanding its importance, very little information is available on PAL activity under heavy metal stress. The effect of copper on PAL was studied in Panax ginseng (Ali et al., 2006) and the influence of cadmium on PAL activity has recently been studied in fronds of Azolla imbricata (Dai et al., 2006). However, more detailed studies focused on time and concentration dynamics are still lacking. In a recent study (Kováčik et al., 2005) on the effect of copper and cadmium in the induction of PAL activity and subsequent formation of polyphenols in Chamomile (Matricaria chamomilla), it is demonstrated that high Cd concentrations caused a stimulatory effect on PAL activity and soluble phenolics accumulation, while high $\mathrm{Cu}$ doses had extreme stimulatory effects on PAL activity and phenolics accumulation in roots. Cd accumulation was higher in the leaf rosettes compared to copper, but the opposite was recorded in case of roots. Speciesspecific changes in expression of phenylalanine ammonia-lyase (PAL) and lignin content were detected in roots of soybean (Glycine max L.) and lupine (Lupinus luteus L.) when treated with different concentrations of cadmium and lead (Chmielowska et al., 2008). The activity of PAL was enhanced in both the plant species at comparatively higher metal concentrations; however, it was not directly correlated with $P A L$ mRNA. This suggests a transcriptional and posttranscriptional control of PAL expression under heavy metals stress. Cadmium-induced changes in total Phenolics, and Phenylalanine Ammonia-lyase activity in fronds of Azolla imbricata has also been recently studied (Dai et al., 2006). In this study, significant increase in total phenolic content, total anthocyanin content as well as PAL activity were also detected during $\mathrm{Cd}$ treatment. The results suggested that anthocyanin, total phenolics and their biosynthesis-related enzyme PAL could have been playing a role in detoxification of $\mathrm{Cd}$ in $A$. imbricate. Some other groups also demonstrated the positive effect of copper in PAL induction in some other plants such as Phyllanthus tenellus Roxb (Laura et al., 2010), soybean seedlings (Sylwiaet al., 2011) and Jatropha curcas L. seedling ( $\mathrm{Gao}$ et al., 2008). Other than $\mathrm{Cd}$ and $\mathrm{Cu}$, Zinc (Zn) also plays an important role in PAL induction and expression (Luo et al., 2010). A positive relation between zinc concentration and induction of PAL has already been established.

\section{Relation between PAL induction and production of polyphenolics}

If PAL level is a limiting factor in phenolic biosynthesis via phenylpropanoid pathway, then different stimuli discussed above causing induction of PAL should also cause an increase in phenolic compound production. Concomitant increase in the level of PAL and phenolic compounds has been demonstrated in many plants. In gherkin seedlings changes in PAL levels after treatment with blue light (Engelsma, 1967a)), long term $\mathrm{R}$ light (Engelsma, 1967b), wounding (Engelsma, 1968), photoperiod (Engelsma, 1969a) and temperature (Engelsma, 1969b; Engelsma, 1970a; Engelsma, 1970b) reflected greater accumulation of hydroxycinnamic acids, the major phenolic in plants. Not only in seedlings but also in fresh potato tissue, incubation under light developed PAL level or chlorogenic acid (Zucker, 1965) suggesting that there is a direct relation between PAL induction and polyphenolic production. Similar increase in PAL level and chlorogenic acid has been described in ethylene treated sweet potato (Imaseki, 1968) and Swede tissues (Rhodes and Wooltorton, 1971). Phenolics in fruits and vegetables represent the major class of antioxidant supplements in our diet (Liang and Kitts 2016). In a metabolomics study it was reported that cinnamic acid and its derivatives such as gallic acid, rution etc. are present in good quantities in plants (Liu et al. 2017). In Actinomycete Streptomyces verticillatus, a correlation between cinnamide production and the levels of PAL has also been demonstrated (Bezanson et al., 1970). 
Recently in a study the importance of PAL even in the treatment of phenylketonuria is reported (de Sousa et al. 2020).

Although flavonoids, flavanols are biosynthetically different from simple phenolics there are many examples of correlations between their increased production and PAL induction. Naringenin in grapefruit (Maier and Hasegawa, 1970), leucoanthocyanins and catechins in strawberry leaf disks (Creasy, 1968) accumulated due to induced expression of PAL. In buckwheat both PAL and anthocyanin production are affected in the same way by R and FR light (Scherfand Zenk, 1967).

Apiin and graveobioside-B formation after illumination of parsley cell cultures coincides with highest PAL activity (Hahlbrock and Wellman, 1970). Even in developing tulip and narcissus anthers, the content of several flavonoids show a direct correlation with PAL activity. High PAL activity is often correlated with active lignification although in non-lignifying tissues the enzyme may also have very high specific activities. In bamboo shoots growing under light, the regions of highest PAL activity are those undergoing most rapid lignifications; while in very young shoot and in already lignified tissue there is little activity (Higuchi, 1966). In another study on soybean the importance of PAL in mitigating biotic stress, more specifically in combating pathogen induced stress was documented (Shine et al., 2016).

PAL and lignification are not correlated in all plants. Very little or no PAL is present in lignifying Eucalyptus leaves (Hillis and Ishikura, 1970) but in buckwheat the highest specific activity is found in the stem apex. In Periploca graeca and in tobacco very high specific activities have been found in young tissues and in the terminal bud (Paynot et al., 1971). Since very young tissues are often conspicuously colored with anthocyanin this should be correlated with PAL levels and the levels of particular polyphenols and anthocyanins. The same observation could be applied during interpreting the results of accumulation of hydroxyl cinnamic esters and flavonoids in some plants. In a study on carrot tissue culture, it has been observed that production of flavonoids was high but with a lower level of PAL (Havir and Hanson, 1968). It seems, from these examples that PAL is not the only site of control of cinnamate metabolism in plants. Swain and Williams cast doubt on the exclusive role of phenylalanine as a flavonoid precursor, although other works (Swain and Williams, 1970) reaffirms the role.

A study on control of flavonoid synthesis in parsley cell suspension cultures may give a better understanding of the situation (Hahlbrock et al., 1976). These cultures do not produce flavone glycosides in dark but when exposed to high intensities of white light they start producing apiin and graveobioside-B, the normal flavone glycosides of parsley. The first stage in the synthesis of these flavones is reflected with a marked increase in the levels of eight enzymes which are probably involved in their synthesis. These enzymes are PAL, cinnamic acid 4-hydroxylase, p-coumarate CoA ligase, chalcone-flavanone isomerase, a glucosyl transferase, an apiosyl transferase, UDP apiose synthetase and an O-methyl transferase. The first three enzymes act upon phenylpropanoid derivatives with maximum activity and start to decline within $15 \mathrm{hr}$ after the onset of continuous illumination. The remaining enzymes which are all concerned with flavonoid synthesis attain maximum activity after $24 \mathrm{hr}$ of illumination and only then do the levels decline. Regulation of the levels of these two sets of enzymes is different. So far this is the most complete study of flavonoid biosynthesis at enzymatic level and this study is quite suitable for describing the role of PAL in flavonoid synthesis.

\section{Conclusion}

Studies so far suggest that PAL acts as a primary control and the other enzymes concerned with subsequent steps in phenylpropanoid metabolism display secondary control. Majority of the studies on PAL have demonstrated that there have been concomitant increases in levels of PAL and of phenolic compounds in many plants and plant tissues under the influence of several external stimuli. Therefore, a detailed study on the gene encoding PAL would widen the horizon of the field of polyphenol research with a chance of advancement in industrial applications.

\section{Conflict of interest statement}

Authors declare that they have no conflict of interest. 


\section{References}

Albert G, Raqeva R and BoudetA M. 1977. Physiol Veg. 15:279.

Ali M A, Hahn E, Paek K. 2006.Copper-induced changes in the growth, oxidative metabolism, and saponin production in suspension culture roots of Panax ginseng in bioreactors. Plant Cell Rep. 25, 1122-1132.

Amrhein N, Gerhardt J. 1979. Superinduction of phenylalanine ammonia-lyase in gherkin hypocotyls caused by the inhibitor, L-alphaaminooxy-beta-phenylpropionic acid. Biochim. Biophys. Acta. 583(4), 434-442.

Amrhein N, Zenk M H. 1971. Z. Pflanzenphysiol. 64:145.

Bezanson G S, Desaty D, Emes A V, Vining L C. 1970. Biosynthesis of cinnamamide and detection of phenylalanine ammonia lyase in Strepromyces verticillatus. Can J Microbiol.16: 147-151

Bezanson GS, Desaty D, Emes AV, Vining LC. 1970. Biosynthesis of cinnamamide and detection of phenylalanine ammonia lyase in Strepromyces verticillatus. Can. J. Microbiol. 16: 147-151.

Biehn W L, Kuc J, Williams E B. 1968. Accumulation of phenols in resistant plants, fungi interaction. Phytopathology. 58:12551260.

Calabrese JC, Jordan DB, Boodhoo A, Sariaslani S, Vannelli T. 2004. Crystal structure of phenylalanine ammonia lyase: multiple helix dipoles implicated in catalysis. Biochemistry 43: 11403-11416.

Camm E.L, Towers G H N. 1977. Phenylalanine ammonia lyase. 169-188. In L. Reinhold, J.B. Harborne and T. Swain (eds.). Progress in Phytochem.vol. 4. Pergammon Press, New York

Camm EL, Towers GHN. 1973. Phenylalanine ammonia lyase. Phytochemistry 12: 961-973 .

Camm, E.L. and G.H.N. Towers. 1977. Phenylalanine ammonia lyase, p. 169-188. In L.Reinhold, J.B. Harborne and T. Swain (eds.). Progress in Phytochem.vol. 4.Pergammon Press, New York.

Chmielowska J, Deckert J, Díaz D. 2008. Activity of peroxidases and phenylalanine ammonialyase in lupine and soybean seedlings treated with copper and an ethylene inhibitor. Biological Lett. 45: 59.67

Christina K, Cheng C, Marsh Jr. H V. 1968. Gibberellic Acid-Promoted Lignification and
Phenylalanine Ammonia-lyase Activity in a Dwarf Pea (Pisum sativum). Plant Physiol. 43, $1755^{-1759 .}$

Creasy L L. 1968.The increase in Phenylalanine Ammonia Lyase activity in strawberry leaf disk and its relation with flavonoid synthesis. Phytochemistry. 7441: 1968.

Dai L P, Xiong Z T, Huang Y, Li M J. 2006. Cadmium-induced changes in pigments, total phenolics, and phenylalanine ammonia-lyase activity in fronds of Azolla imbricata. Environ. Toxicol. 21, 505-512.

de Sousa IP, Gourmel C, Berkovska O, Burger M, Leroux JC. 2020. A microparticulate based formulation to protect therapeutic enzymes from proteolytic digestion: phenylalanine ammonia lyase as case study. Scientific Reports 10:3651

Dixon R A , Fuller K W. 1976. Effects of synthetic auxin levels on phaseollin production and phenylalanine ammonialyase (PAL) activity in tissue cultures of Phaseolus vulgaris $L$. Physiol. Plant Pathol. 9: 299-312.

Dixon RA, Fuller KW. 1976. Effects of synthetic auxin levels on phaseollin production and phenylalanine ammonialyase (PAL) activity in tissue cultures of Phaseolus vulgaris L. Physiol Plant Pathol. 9: 299-312

Duchesne M, Fritig B, Hirth L. 1977. Phenylalanine ammonia lyase in tobacco mosaic virus infected hypersensitive tobacco. Density labeling evidence of de novo synthesis. Biochem Biophysics Acta. 485(2), 465-481

Engelsma G. 1967a. Photo induction of phenylalanine deaminase in gherkin seedlings.Effect of blue light. Planta. 75: 207219.

Engelsma G. 1967b. Photo induction of phenylalanine deaminase in gherkin seedlings. Effect of red and far red light. Planta. 77: 49-57.

Engelsma G. 1969a. The influence of light of different spectral regions on the synthesis ofphenolic compounds in gherkin seedlings, in relation to photomorphogenesis. VI. Phenolsynthesis and photoperiodism. Acta Bot Neer.18: 347-352

Engelsma G. 1969b. Low-temperature dependent development of phenylalanine ammonia-lyase in gherkin hypocotyls. Naturwissenschaften. 56(11): 563 .

Engelsma G. 1970a. Photoinduction of phenylalanine deaminase in glherkin seedlings. 
IV. The role of the temperature. Planta.90: 133141.

Engelsma G. 1970b. Low-temperature effects on phenylalanine ammonia-lyase activity in gherkin seedlings. Planta. 91: 246-254.

Engelsma, G., 1968. Photoinduction of plienylalanine deaminase in gherkin seedlings. III. Effects of excision and irradiation on enzyme development in hypocotyl segments. Planta. 82: 355-368.

Fosket D E. 1980. Plant Growth Substances [Proc10 $^{\text {th }}$ International Conference on Plant Growth Substances, 19793 (Skoog) 362 Springer.

Fritz RR, Hodgins DS, Abell CW. 1976. Phenylalanine ammonia lyase: induction and purification from yeast and clearance in mammals. J. Biol. Chem. 251: 4646-4650.

Fry S C. 1979. Phenolic components of the primary cellwall and their possible role in the hormonal regulation of growth. Planta, 146: 343 .

Gao S, Yan R, Cao M, Yang W, Wang S,Chen F. 2008. Effects of copper on growth, antioxidant enzymes and phenylalanine ammonia-lyase activities in Jatropha curcas L. seedling. Plant Soil Environ. 54 (3): 117-122.

Hahlbrock K, Wellman E. 1970. Light-induced flavone biosynthesis and activity of phenylalanine ammonia-lyase and UDP-apiose synthetase in cell suspension cultures of Petroselinum hortense. Planta. 94: 236-239.

Hahlbrock K, Knobloch K, Kreuzaler F, Potts J R M, Wellmann E. 1976. Light-induced synthesis of flavonoid glycosides in cell suspension cultures of Petroselinum hortense. Eur. J. Biochem. 61: 199-206.

Hahlbrock K, Knobloch KH, Kreuzaler F, Potts JR, Wellmann E. 1976. Coordinated induction and subsequent activity changes of two groups of metabolically interrelated enzymes. Lightinduced synthesis of flavonoid glycosides in cell suspension cultures of Petroselinum hortense. Eur J Biochem. 61(1): 199-206.

Hanson K R, Havir E A. 1981. Secondary Plant Products (Conn, E E , ed ), Ch 20, p 577 [Vol 7 of The Biochemistry of Plants A Comprehensive Treatise (Stumpf, $\mathrm{P} \mathrm{K}$ and Conn, E E , eds in chief)] Academic Press, New York.

Hanson KR, Havir EA. 1968. L-phenylalanine ammonia lyase. II. Mechanism and kinetic properties of the enzyme from potato tubers.
Biochemistry 7: 1904-1914.

Hanson KR, Havir EA. 1970. L-phenylalanine ammonia lyase. IV. Evidence that the prosthetic group contains a dehydroalanyl residue and mechanism of action. Arch. Biochem. Biophys. 141: 1-17.

Havir E A, Hanson K R. 1968. L-phenylalanine ammonia-lyase. II. Mechanism and kinetic properties of the enzyme from potato tubers. Biochemistry. 7(5): 1904-1914.

Havir E A.1981. Modification of L-phenylalanine ammonia-lyase in soybean cell suspension cultures by 2-aminooxyacetate and L-2aminooxy-3-phenylpropionate. Planta. 152: 124.

Heinzmann U, Seitz U. 1977. Synthesis of phenylalanine ammonia-lyase in anthocyanincontaining and anthocyanin-free callus cells of Daucus carota L. Planta. 135(1), 63-67.

Higuchi T. 1966. Role of phenylalanine deaminase and tyrase in the lignification of bamboo. Agric. Biol. Chem. 30: 667-673.

Hillis W E, Ishikura N. 1970. The biosynthesis of polyphenols in tissues with low phenylalanine ammonia lyase activity. Phytochemistry. 9: 1517-1517.

Hodgins DS. 1971. Yeast phenylalanine ammonia lyase. Purification, properties, and the identification of catalytically essential dehydroalanine. J. Biol. Chem. 246: 29772985.

Holton TA, Cornish EC. 1995. Genetics and biochemistry of anthocyanin biosynthesis. Plant Cell 7: 1071-1083.

Hossam S El-Beltagi, Osama K Ahmed, Wael ElDesouky. 2011. Effect of low doses gamma irradiation on oxidative stress and secondary metabolites production of rosemary (Rosmarinus officinalis L.) callus culture. Rad. Phys. Chem. 80: 968-976.

Hyodo H, Yang S F. 1971. Ethylene-enhanced synthesis of phenylalanine ammonia-lyase in pea seedlings. Plant Physiol. 47(6): 765-770.

Imaseki H, Uchiyama M, Uritani. 1968. Effect of ethylene on the inductive increase in metabolic activities in sliced sweet potato roots. Agr. Biol. Chem. Japan. 32: 387-389.

Jones H D, Northcote H. 1981.Induction by hormones of phenylalanine ammonia-lyase in bean-cell suspension cultures. Eur. J. Biochem. 116, 117-125.

Jun S, Steven A. Sattler SA, Gabriel S. Cortez GS, 
Vermerris W,Sattler S, Kang C. 2018. Biochemical and structural analysis of substrate specificity of a phenylalanine ammonia-lyase. Plant Physiol. 176: 1452-1468.

Koukol J, Conn EE. 1961. Metabolism of aromatic compounds in higher plants. IV. Purification and properties of phenylalanine deaminase of Horden vulgare. J. Biol. Chem. 236: 26922698.

Kováčik J, Klejdus B. 2008. Dynamics of phenolic acids and lignin accumulation in metal-treated Matricaria chamomilla roots.Plant Cell Rep. 27:605-615.

Lamb C J. 1982. Effects of competitive inhibitors of phenylalanine ammonia-lyase on the levels of enzymes of phenylpropanoid metabolism in Solanum tuberosum. Plant Cell and Environment. 5:471-475.

Lamb C J.1979. Regulation of enzyme levels inphenylpropanoid biosynthesis. Characterisation of the modulation by light and pathway intermediates. Arch. Biochem. Biophys. 192: 311-317.

Lamb C. J, Rubery P H. 1976. Photocontrol of chlorogenic acid biosynthesis in potato tuber discs. Phytochemistry. 15: 665-668.

Lee A, Hadwiger, Schwochau E M. 1971. Ultraviolet light-induced formation of pisatin and phenylalanine ammonia lyase. Plant Physiol. 47(4): 588-590.

Liang N, Kitts DD. 2016. Role of chlorogenic acids in controlling oxidative and inflammatory stress conditions. Nutrients. 8: 16.

Liu J, Yuana Y,1, Wua Q, Zhaoa Y, Jianga Y, Johna A, Wena L, Lia T, Jiana Q, Yanga B. 2017. Analyses of quality and metabolites levels of okra during postharvest senescence by $1 \mathrm{H}$-high resolution NMR. Postharvest Biol. Technol. $132,171-178$.

Luo Z B, HE X J, Chen L, Tang L, Gao S, Chen F. 2010. Effects of zinc on growth and antioxidant responses in Jatropha curcas seedlings. Int. J. Agric. Biol. 12, 1.

Maier V P, Hasegawa S. 1970. L-Phenylalanine ammonia-lyase activity and naringenin glycoside accumulation in developing grapefruit. Phytochemistry. 9: 139-144.

Minamikawa T, Uritani. 1965a. Phenylalanine ammonia-lyase in sliced sweet potato roots. J Biochem. 57: 678-688.

Nitsch C, Nitsch J P. 1966. Effect de la lumieresurl'induction de la phenylalanine deaminasedans les tissues de tubercule d' Helianthus tutberosus L. Compt. Rend. 262: 1102-1105.

Noe W, Seitz H U. 1982. Induction of de novo synthesis of phenylalanine ammonia-lyase by L-a-aminooxy-b-phenyl-propionic acid in suspension cultures of Daucus carota L. Planta. 154: 454-458.

Ogata K, Uchiyama K, Yamada H. 1967. Metabolism of aromatic amino acid in microorganisms. Part I: formation of cinnamic acid from phenylalanine. Agric. Biol. Chem. 31: 200-206.

Owen, C. 1982. Biochemical aspects of copper. Park Ridge, NJ: Noyes

Paynot M, Martin C, Giraud M. 1971. Phenylalanine ammonia-lyase activity and tobacco mosaic virus hypersensitivity of Nicotiana tabacum var. xanthine. 273(4): 537539.

Pegg G F, Sequeria L. 1968. Stimulation of aromatic biosynthesis in tobacco plants infected with Pseudomonas solanacearum. Phytopathology. 58: 476-483.

Rhodes M J C, Wooltorton S C. 1971. The effect of ethylene on the respiration and on the activity phenylalanine ammonia lyase in Swede and parsnip root tissue. Phytochemistry. 10: 1989.

Riov J, Monselise S P, Kahan R S. 1968. Effect of gamma radiation on phenylalanine ammonialyase activity and accumulation of phenolic compounds in citrus fruit peel. Radiat. Bot. 8: 463-466.

Riov J, Monselise S P, Kahan R S. 1969. Ethylenecontrolled induction of phenylalanine ammonia-lyase in citrus fruit peel. Plant Physiol. 44(5): 631-635.

Riov J, Monselise S P, Kahn R S. 1969.Ethylenecontrolled induction of phenylalanine ammonia-lyase in citrus fruit peel. Plant Physiol. 44: 631-635.

Santiago L J M, Louro R P L, Oliveira D E D. 2000. Compartmentation of phenolic compounds and phenylalanine ammonia-lyase in leaves of Phyllanthus tenellus Roxb. and their induction by copper sulphate. Ann. Bot. 86: 1023-1032.

Scherf H, Zenk M H. 1967. Induction of anthocyanin and phenylalanine ammonia-lyase formation by a high energy light reaction and its control through the phytochrome system. Pflanzenphysiol. 56: 203-06.

Schopfer P, Mohr H. 1972. Phytochrome-mediated 
induction of phenylalanine ammonia-lyase in mustard seedlings: A contribution to eliminate some misconceptions. Plant Physiol. 49(1): 8-10.

Shields S E, Wingate V P, Lamb C J. 1982. Dual control of phenylalanine ammonia-lyase production and removal by its product cinnamic acid. Eur. J. Biochem. 123: 389-395.

Shine MB, Yang U, El Habbak M, Nagyabhyru P, $\mathrm{Fu}$ D, Navarre D, Ghabrial S, Kachroo P, Kachroo A. 2016. New Physiologist. 212 (3): 627-636.

Sikora LA, Marzluff GA. 1982. Regulation of 1phenylalanine ammonia lyase by lphenylalanine and nitrogen in Neurospora crassa. J. Bacteriol. 150: 1287-1292.

Sondheimer E, Tzou D S, Galson E C. 1968. Abscisic acid levels and seed dormancy. Plant Physiol. 43(9): 1443-1447.

Sprada S P, Arasimowicz-Jelonek A, Podgórska M, Deckert J. 2011. Activation of phenylpropanoid pathway in legume plants exposed to heavy metals. Part I. Effects of cadmium and lead on phenylalanine ammonia-lyase gene expression, enzyme activity and lignin content Acta Biochim. Pol. 58: 211-216.

Swain T, Williams C A.1970. The role of phenylalanine in flavonoid biosynthesis. Phytochemistry. 9: 2115-2115.

Trewavas A J. 1979. What is the molecular basis of plant hormone action? Trends in Biochem. Sci. 4: 199.

Watanabe SK, Hemandez-Velazco G, IturbeChinas F, Lopez-Mungia A. 1992. Phenyl alanine ammonia lyase from Sporidiobolus pararoseus and Rhodosporidium toruloides: application for phenylalanine and tyrosine deamination. World J. Microbiol. Biotechnol. 8: 406-410.

Weisshaar B, Jenkins GI. 1998. Phenylpropanoid biosynthesis and its regulation. Curr. Opin. Plant Biol. 1: 251-257.

Zucker M. 1965. Induction of phenylalanine deaminase by light and its relation to chlorogenic acid synthesis in potato tuber tissue. Plant Physiol. 40(5): 779-784.

Zucker, M. 1972. Light and enzymes. Annu. Rev. Plant Physiol. 23: 133-156.

\section{How to cite this article:}

Talukder, P., 2020. Regulation of induction of phenylalanine ammonia lyase and its role in production of phenolic compounds in plants. Int. J. Curr. Res. Biosci. Plant Biol. 7(6), 55-63.

doi: https://doi.org/10.20546/ijcrbp.2020.706.006 